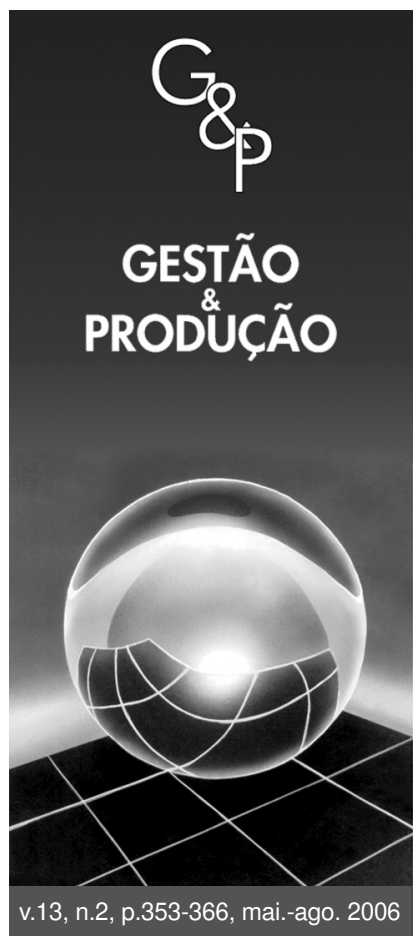

\title{
A INTEGRAÇÃO EMPRESA CLIENTE - OPERADOR LOGÍSTICO: UMA ANÁLISE NA CADEIA AUTOMOTIVA
}

\author{
Leonel Mazzali \\ Marina Milan
}

Universidade São Marcos, Av. Nazaré, 900, Ipiranga, CEP 04262-100, São Paulo, Brasil,

e-mails: leonel_mazzali@uol.com.br, marinamilan@uol.com.br

\section{Resumo}

O trabalho identifica e analisa os mecanismos de coordenação entre operadores logísticos e empresas clientes, na cadeia automotiva, recuperando as principais abordagens sobre parcerias logísticas. Énfase especial é dedicada ao modelo proposto por Lambert et al. (1996). A metodologia assenta-se na descrição e análise de três estudos de caso. De modo geral, a pesquisa evidenciou um elevado grau de integração entre as empresas clientes pertencentes à indústria de autopeças e os operadores logísticos. Os três casos analisados podem ser enquadrados como tipo III - parceria altamente integrada - apresentando, no entanto, diferenças entre os mecanismos de coordenação utilizados, associados ao tipo e à natureza da parceria.

Palavras-chave: operador logístico, parcerias, mecanismos de coordenação e grau de integração.

\section{Introdução}

No período recente, o acirramento da competição e a crescente sofisticação do consumo geraram um ambiente turbulento, a capacidade de atender "em tempo" a uma demanda instável emerge como elemento central da construção e da manutenção da vantagem competitiva. Nesse contexto, a logística se coloca como espaço privilegiado de decisão, seja sob a ótica da redução de custos, seja sob a ótica da diferenciação/inovação. É importante considerar, segundo Christopher (2001), que, à medida que as distinções entre os produtos diminuem, o fornecimento de serviços se torna o instrumento essencial de diferenciação e, nesse âmbito, a competência logística assume papel relevante ao disponibilizar o produto em tempo real. A preocupação crescente com os sistemas de resposta rápida ao consumidor e com programas de fornecimento just in time são evidências de que a gestão eficiente da logística oferece a oportunidade de agregar serviços potencialmente criadores de valor.
O conceito de logística, segundo Novaes (2001), sofreu transformação ao longo do tempo. Em primeiro lugar, deixou de estar atrelado somente ao âmbito interno da empresa, passando a ser visualizado no âmbito da cadeia produtiva. Em segundo lugar, passou a ser encarado como um conjunto de competências específicas, abrindo espaço para a emergência de agentes especializados.

A dimensão da logística no interior da estratégia competitiva "baseada no tempo" resultou no desenvolvimento de novas estruturas organizacionais, em cujo centro estão a externalização de atividades "não essenciais" (Miles e Snow, 1987) e o desenvolvimento de novas relações com fornecedores, distribuidores e clientes (Christopher, 2001 e Lamning 1993). O resultado é uma nova configuração produtiva - a cadeia de suprimentos - no centro da qual está a gestão "em rede" de um conjunto de organizações, que passa a atuar de forma integrada e sincronizada, em termos dos 
fluxos físico e de informações. A gestão "em rede" constitui um arranjo organizacional no interior do qual emerge "um ambiente suscetível de provocar a emergência de externalidades dinâmicas (pecuniárias, tecnológicas, etc.), complementaridades e fenômenos cumulativos, notadamente no plano das competências." (Guilhon, 1992: 573).

Considerando que, de modo geral, as atividades logísticas não se constituem no foco principal das empresas industriais e comerciais, a opção é a terceirização, a qual exige a coordenação de diferentes agentes - transportadores, armazéns, consultoriais, dentre outros -, trazendo à cena um novo protagonista - o operador logístico. $\mathrm{O}$ operador logístico é "um fornecedor de serviços logísticos integrados, capaz de atender a todas ou quase todas as necessidades logísticas de seus clientes de forma personalizada." (Fleury et al., 2000: 134).

Segundo Novaes (2001), a incorporação dos operadores logísticos nas cadeias de suprimentos é recente; as parcerias estão se formando, tornando-se crescentemente uma alternativa à tradicional empresa verticalmente integrada. No entanto, Boyson et al. (1999) lembram que o desenvolvimento de relacionamentos logísticos pode se transformar, de um lado, em instrumento de redução de custos e construção de vantagem competitiva, de outro, em alguns casos, pode se constituir em fonte de falhas, ineficiências e desapontamentos, em um ambiente marcado por objetivos imprecisos, expectativas irrealistas e falhas nos arranjos entre as partes envolvidas.

Assim, este trabalho investiga o processo de gestão interorganizacional imanente ao relacionamento entre a empresa cliente e o operador logístico, no interior da cadeia automotiva. Mais precisamente, objetiva identificar mecanismos efetivos para a organização, a operação e o controle da parceria, na cadeia automotiva, partindo do pressuposto de que o sucesso das parcerias com agentes especializados nas atividades logísticas depende do tipo e da natureza do arranjo subjacente à relação.

O trabalho está estruturado em sete seções. A primeira é introdutória. Na segunda, são discutidos o conceito e as principais características das parcerias logísticas. A terceira apresenta e discute o modelo proposto por Lambert et al. (1996), constituindo-se em um método sistemático de formação, implementação e administração de parcerias. A quarta apresenta os procedimentos metodológicos da pesquisa empreendida. A quinta e a sexta procedem, respectivamente, à apresentação e à análise dos resultados. Finalmente, na sétima, algumas conclusões são indicadas e apresentadas possibilidades para futuras pesquisas.

\section{Parcerias logísticas - conceito e características}

A figura do operador logístico e suas funções no interior da cadeia de suprimentos são relativamente recentes. Se- gundo Knemeyer e Murphy (2005: 708), "a pesquisa acadêmica voltada ao estudo do fenômeno era virtualmente inexistente antes de 1990, particularmente nos EUA, e a literatura podia ser caracterizada como descritiva e demográfica." Atualmente, emergiram novos enfoques assentados na abordagem da administração estratégica (Sinkovics e Roath, 2004), na teoria das competências estratégicas (Halldorsson e Skjott-Larsen, 2004) e na perspectiva do marketing de relacionamento (Moore, 1998).

Quando uma empresa decide utilizar um agente especializado na coordenação de todas as suas operações logísticas, ela se envolve em uma relação freqüentemente denominada de parceria logística. Existem várias definições de parceria logística. Ellram (1995: 37) define parceria logística como:

um acordo entre um comprador e um fornecedor que envolve um comprometimento sobre um longo período de tempo, incluindo o compartilhamento de informações, de riscos e de recompensas derivadas do relacionamento.

Para Lambert et al. (1999: 167), "embora essa definição aponte para alguns aspectos da parceria, ela é incompleta, não enfatiza adequadamente a necessidade de customização do relacionamento." Nesse sentido, os autores definem parceria como:

uma relação adaptada às transações baseada na confiança mútua, transparência, compartilhamento de risco e de benefícios, propiciando uma vantagem competitiva e uma performance superior àquela obtida se as empresas atuassem individualmente. (p. 167).

Como se percebe, Lambert et al. não consideram que a parceria deva, necessariamente, estar associada a uma forte integração entre os agentes envolvidos. Existem gradações ou escalas que refletem o nível de aprofundamento da relação entre as partes. Algumas parcerias envolvem laços estreitos e compartilhamento significativo entre os agentes, enquanto outras refletem um baixo grau de integração, situando-se, no entanto, num estágio superior ao da simples transação de mercado.

Não é uma tarefa fácil erigir uma parceria e, diante das inúmeras experiências que resultaram em insucesso, vários autores direcionaram a pesquisa para a explicitação das causas das falhas nas parcerias. Lieb e Randall (1996) sugerem que o maior problema está associado à perda potencial de controle sobre as atividades logísticas e às incertezas sobre o nível do serviço oferecido, questões estas atinentes ao verdadeiro custo da externalização. Para Ellram (1995), os principais fatores que conduzem ao insucesso na parceira são: sistema deficiente de comunicação, ausência de suporte da alta gerência, falta de confiança, planejamento deficiente, ausência de direção estratégica e de objetivos compartilhados. 
Em síntese, a maioria das causas do insucesso das parcerias pode ser enquadrada em duas categorias genéricas, sugeridas por Stuart e McCutcheon (1995): (1) conflito de percepção sobre o grau apropriado de integração entre as partes; e (2) processo inadequado de construção da parceria.

Embora existam na literatura vários modelos ou processos associados à implementação e ao desenvolvimento de parcerias, com destaque para Gardner et al. (1994), Ellram (1995), Bagchi e Virum (1996) e Stuart (1993), na visão de Lambert et al. (1999: 168):

Os modelos são boas ferramentas para determinar a adequação (ou não) da externalização, mas eles não vão além da indicação dos principais problemas, uma vez tomada a decisão. Nenhum deles oferece um guia sobre o tipo de relacionamento - baseado em contrato de curto prazo, contrato de longo prazo e ou formação de parceria.

Destacam, ainda, os referidos autores que:

Os modelos também assumem que todas as parcerias são iguais. Isto é, embora a externalização possa se constituir em uma decisão correta e necessária, podem ocorrer decisões incorretas no que se refere ao tipo específico de relação. Nesse sentido, as falhas têm origem não na externalização em si, mas na falta de acordo entre as partes quanto ao tipo de arranjo a ser utilizado para gerir a relação.

Esses são os aspectos centrais que levaram à escolha do modelo proposto pelos autores, aprofundado na seção seguinte. Em primeiro lugar, o foco é dirigido ao tipo mais apropriado de parceria (integração), considerando o ambiente que circunscreve a relação - natureza dos objetivos perseguidos e compatibilidade entre as empresas participantes. Em segundo lugar, o modelo explicita e analisa o processo de construção e de sustentação da relação interorganizacional entre a empresa cliente e o operador logístico, a partir da identificação e da avaliação dos mecanismos de coordenação das atividades e dos processos conjuntos.

\section{Diferentes níveis de integração no interior das parcerias: o modelo de Lambert et al.}

Lambert et al. (1996) apresentam um método sistemático de formação, implementação e administração de parcerias, desenvolvido a partir de análise aprofundada de 18 relacionamentos, envolvendo, de um lado, empresas clientes de diversos setores e, de outro, operadores logísticos e transportadoras. Após o desenvolvimento do modelo, este foi testado utilizando oito relacionamentos adicionais.
O modelo tem três grandes componentes: direcionadores, facilitadores e mecanismos de gestão. Os três, em conjunto, configuram o provável resultado da parceria.

Os direcionadores constituem as razões que impelem a formação da parceria. São benefícios estratégicos resultantes do fortalecimento da relação, como aumento da eficiência/redução de custos na utilização de ativos e incremento nos serviços oferecidos ao consumidor. Se ambas as partes não percebem e não visualizam a possibilidade de obter benefícios significativos na relação, então, a parceria tenderá ao fracasso.

Os facilitadores provêm um ambiente propício ao crescimento e à manutenção da relação. Os autores identificam quatro principais facilitadores - filosofias, técnicas similares, mutualidade e simetria entre as corporações - e três adicionais que, de modo geral, não se fazem presentes em todas as relações, mas que tenderiam a fortalecê-las - exclusividade, proximidade física e experiência anterior. Os facilitadores refletem o grau de aderência entre as partes, isto é, o grau de compatibilidade entre as duas empresas.

O ponto central ressaltado pelos autores diz respeito à existência de vários graus de integração, identificados, de modo semelhante a Weber (1944), como três tipos ideais: tipo I, tipo II e tipo III. No tipo I, as organizações envolvidas reconhecem cada uma como parceira, porém coordenam e planejam as atividades em base limitada. A parceria, usualmente, possui um foco de curto prazo e envolve somente uma divisão ou área funcional no interior de cada organização. No tipo II, as organizações envolvidas evoluem da simples coordenação em direção à integração das atividades. Embora não se espere que a relação dure para sempre, a parceria passa a ter um horizonte de mais longo prazo. Ademais, múltiplas divisões e funções no interior das empresas passam a estar envolvidas. Finalmente, no tipo III, as organizações atingem um significativo grau de integração. Cada parte enxerga a outra como uma extensão da sua própria organização, não existindo uma data para o término da parceria.

A combinação de forças dos direcionadores e dos facilitadores determina o potencial para a integração. Enquanto o nível dos direcionadores e dos facilitadores determina o grau mais apropriado de integração, a forma e o conteúdo do processo dependem dos mecanismos de gestão da relação interorganizacional. Segundo o modelo, os mecanismos de gestão determinam como e se a integração é alcançada.

Os mecanismos de gestão estão associados à forma de coordenação das atividades conjuntas e ao processo de construção e de sustentação da parceria. No que se refere à coordenação das atividades conjuntas, destacam-se o planejamento, o controle das operações e o sistema de comunicações. No âmbito do processo de construção e 
de sustentação da parceria, os principais elementos são compartilhamento de riscos e de benefícios, confiança e comprometimento entre as partes, estilo do contrato, escopo da parceria e natureza dos investimentos.

O planejamento, componente chave para parcerias efetivas, pode envolver tanto o compartilhamento de planos existentes quanto o desenvolvimento conjunto de objetivos estratégicos, adicionando flexibilidade e coesão à parceria. Lambert et al. (1996), ao analisarem o planejamento, consideram estilo, nível e conteúdo.

O controle de operações envolve a medida e a análise do desempenho, além da habilidade para proceder a mudanças.

No âmbito do sistema de comunicação, os autores fazem uma análise das comunicações rotineiras e não rotineiras. No que se refere às rotineiras, são considerados os sistemas eletrônicos de comunicação entre empresas, além dos instrumentos tradicionais. Quanto às comunicações não rotineiras, são abordados os aspectos de planejamento e nível hierárquico em que elas ocorrem.

A troca de informações constitui um construto central do estudo das relações interorganizacionais. Para Bowersox et al. (1989: 225): “o compartilhamento da informação é a cola que mantém os aliados como tal. (...) A troca completa de informação é essencial para assegurar a sincronização entre as operações do usuário e as do fornecedor."

O compartilhamento de riscos e de benefícios, segundo La Londe e Cooper (1989) e Bowersox et al. (1989) aparece como um componente central da construção das parcerias logísticas. A justiça na divisão de riscos e benefícios inerentes às transações implica no comprometimento entre as partes, sustentando indefinidamente a relação, reduzindo os conflitos e o risco do comportamento oportunista. O conflito se caracteriza pelo desacordo entre as partes, constituindo-se, segundo Dwyer et al. (1987), em um componente central e inevitável do relacionamento. Nesse âmbito, o estilo do contrato e a confiança emergem como elementos decisivos.

Quanto ao estilo do contrato, Lambert et al. (1996) dão ênfase ao grau de detalhe e ao período de tempo. Quando as partes estão realmente integradas, um documento delineando a filosofia básica e a visão geral da parceria é suficiente. Nesse sentido, quanto maior o grau de integração entre as partes, menor a especificidade dos contratos, ou inexistentes.

Ter confiança é acreditar que o outro irá cumprir as suas obrigações. A confiança está associada à reputação e ao processo de relacionamento ao longo do tempo. Assim, além dos aspectos técnicos e financeiros, são fundamentais a freqüência e o comprometimento na transação. A propósito, Williamson (1985) sugere que o comportamento oportunista tenderá a desaparecer se as partes forem mais transparentes e honestas.
Lambert et al. (1996: 11) descrevem o escopo da parceria como "o número, a complexidade das atividades de agregação cobertas e a relevância da parceria para os negócios de cada parceiro". Para os autores, a parceria é tanto mais forte quanto maior o escopo de atividades envolvido.

Finalmente, o volume e o tipo - ativos específicos, tecnologia e recursos humanos - dos investimentos compartilhados refletem um alto grau de interdependência financeira, fortalecendo a parceria.

Vale destacar que Bolumole (2003) desenvolveu uma abordagem muito semelhante, visando avaliar o papel e a posição do operador logístico. O autor identificou quatro variáveis que influenciam o papel do operador logístico: orientação estratégica da organização cliente (foco interno/foco na cadeia de suprimentos), percepção da funcionalidade do operador logístico (redução de custos/desenvolvimento de recursos e de competências), natureza da relação cliente-operador logístico (transacional/alianças bilaterais/parcerias estratégicas) e extensão da terceirização das atividades logísticas (operacional/tática/estratégica). À medida que a função do operador logístico se amplia (do nível operacional para o estratégico), o foco da empresa cliente se desloca para a cadeia de suprimentos e a percepção da funcionalidade do operador caminha para o desenvolvimento de competências, a interação operador logístico-empresa cliente se aproxima do tipo III do modelo proposto por Lambert et al.

\section{Procedimentos metodológicos}

A pesquisa é exploratória e do tipo qualitativo. Seguindo esse caminho, não se pretende enumerar ou medir os eventos estudados por meio de métodos estatísticos, mas sim obter dados descritivos sobre as relações entre operadores logísticos e as empresas clientes, na cadeia automotiva.

A cadeia automotiva foi selecionada para análise tendo em vista as mudanças organizacionais, a partir dos anos 80 do século XX, capitaneadas pelas montadoras de veículos com foco no denominado "fornecimento enxuto" (lean supply), em cuja base está a filosofia just in time - produção de pequenos lotes, objetivando a redução de estoques e o aumento da qualidade - e um novo padrão de relacionamento com os fornecedores de autopeças que traz as atividades logísticas para o centro das atenções.

O procedimento metodológico adotado é o estudo de casos múltiplos, dado que se pretende aprofundar a análise do processo de gestão do relacionamento entre os operadores logísticos e seus clientes, obtendo uma visão do tipo e da natureza da interação.

A escolha dessa abordagem se fundamenta em Yin (2001: 21): 
(...) a clara necessidade pelos estudos de caso surge do desejo de entender fenômenos sociais complexos. Em resumo, o estudo de caso permite uma investigação para se preservar as características holísticas e significativas dos eventos da vida real - tais como ciclos de vida individuais, processos organizacionais e administrativos, (...).

Cabe esclarecer que, para o autor (p. 68):

(...) a escolha entre projetos de caso único ou de casos múltiplos permanece dentro da mesma estrutura metodológica - e nenhuma distinção muito ampla é feita entre o assim chamado estudo de caso clássico (isto é, único) e estudos de casos múltiplos.

Continua o referido autor:

Projetos de casos múltiplos possuem vantagens e desvantagens distintas em comparação aos projetos de caso único. As provas resultantes de casos múltiplos são consideradas mais convincentes, e o estudo global é visto, por conseguinte, como sendo mais robusto.

Nesse sentido, optou-se pelo estudo de casos múltiplos, considerando a possibilidade de investigação das relações entre três dos maiores operadores logísticos da região da Grande São Paulo - denominados OL1, OL2 e OL3 - e as suas respectivas empresas clientes - denominadas EC1, EC2 e EC3 -, com atuação destacada na cadeia automotiva.

A pesquisa de campo utilizou-se do método qualitativo, por se caracterizar por um foco maior na compreensão dos fatos que propriamente na sua mensuração. A técnica de obtenção de dados foi a entrevista, pois segundo Selltiz et al. (1974: 267):

Numa entrevista - como o entrevistado e a pessoa entrevistada estão presentes no momento em que as perguntas são apresentadas e respondidas - existe a oportunidade para maior flexibilidade para a obtenção de informações; além disso, o entrevistador tem oportunidade para observar a pessoa e a situação total a que responde.

Foram efetuadas seis entrevistas "em profundidade", no período de junho a agosto de 2005, com os gerentes responsáveis pela logística das empresas clientes e com os gerentes das respectivas operadoras. Nesse sentido, foi observada a colocação de Baba (1988), apontando para a importância da análise das visões dos dois lados da parceria.

As entrevistas tiveram uma duração média de quatro horas, apoiadas em um roteiro prévio baseado no referencial desenvolvido por Lambert et al. (1996). Ressalte-se o fato de que os entrevistados se dispuseram a discorrer com profundidade sobre os assuntos abordados. Dos três grandes componentes que integram o modelo - direcionadores, facilitadores e mecanismos de gestão - foram privilegiados os mecanismos de gestão. Os mecanismos de gestão expressam a perspectiva dos operadores logísticos e das empresas clientes quanto ao grau de integração entre as partes. Em primeiro lugar, por terem por referência o fluxo de materiais e de informação. Em segundo lugar, estão associados ao esforço para a superação das fronteiras organizacionais, em particular no âmbito da formação de equipes multifuncionais.

$\mathrm{O}$ roteiro foi dividido em três partes. A primeira com perguntas atreladas ao planejamento das atividades conjuntas, ao controle das operações e ao sistema de comunicações. A segunda abordou as formas de compartilhamento de riscos e de benefícios, a confiança entre as partes, o estilo do contrato, o escopo da parceria e a natureza dos investimentos conjuntos efetivados. Finalmente, a terceira identificou a trajetória da parceria.

\section{Descrição dos resultados}

Nessa seção são apresentadas as características gerais das empresas e a configuração de cada parceria.

\subsection{Relacionamento OL1/EC1}

A OL1 surgiu nos EUA, em 1933, como transportadora de materiais de construção. Atualmente, opera com o gerenciamento de cadeias de suprimento e soluções de transporte, com filiais em quatro continentes, 30.000 funcionários e uma frota de 170 mil veículos. Em 1995, a OL1 abriu filiais na América do Sul, com unidades na Argentina e no Brasil. As operações no Brasil iniciaramse com a compra de uma empresa especializada no transporte de automóveis nos vários modais disponíveis. A empresa instalou-se com a meta de gerenciar o transporte de autopeças fabricadas no Brasil para a fábrica de automóveis da EC1, em Rosário, na Argentina. Faturando R\$ 150 milhões, no Brasil, em 2004, com 620 funcionários, a OL1 atende a 31 clientes dos setores automotivo, artigos de consumo e equipamentos de escritório.

A EC1 possui, atualmente, quatro complexos industriais no País, nos Estados de São Paulo e do Rio Grande do Sul. Ao planejar a instalação da planta em Rosário, na Argentina, em 1997, a EC1 levou em consideração a existência do grande parque produtor de autopeças no Estado de São Paulo, que já fornecia para a empresa. Além da distância entre os fornecedores, no Brasil, e a montadora na Argentina, havia o problema da burocracia alfandegária. Assim, a EC1 decidiu contratar a OL1, delegando a responsabilidade pela logística das peças, no contexto do sistema Milk Run. Ressalte-se que, dentre as atividades logísticas, a OL1 ficou encarregada de proceder ao desembaraço alfandegário. 
EC1 e OL1 coordenam a coleta de peças em 270 fornecedores, por meio de 100 rotas diferentes, 500 coletas semanais e 250 viagens semanais à Argentina, além de gerenciar o retorno de embalagens. A carga coletada nos fornecedores é consolidada no Centro de Distribuição da OL1, em São Paulo, e enviada, em carretas, para Rosário.

No desenvolvimento da relação entre as empresas, duas dificuldades surgiram: a manutenção da consistência do pedido e a implantação do sistema Milk Run junto aos fornecedores da EC1. No processo de implantação do Milk Run, a OL1 teve que ajudar os fornecedores a se adaptarem ao novo sistema, a partir de um programa de assessoria voltado à organização dos processos e à obtenção de "disciplina" no fornecimento. Na opinião dos entrevistados, a maioria das empresas não estava preparada para trabalhar com o sistema, fazendo-se necessárias grandes alterações no sistema de produção.

No que se refere ao planejamento, na visão do gerente entrevistado da OL1: "A OL1 trabalha com planos de melhoria contínua em todas as operações. No início das operações com um novo cliente, as reuniões são, no mínimo, semanais, envolvendo diversos times multidisciplinares, como sistemas, produção e suprimentos. Quando o processo está implantado, como o da ECl, as reuniões passam a ser mensais. As reuniões envolvem diferentes níveis hierárquicos, incluindo as diretorias, que estabelecem estratégias de atuação conjuntas". O entrevistado ressalta um comprometimento muito grande para com o planejamento: "chegamos a desenvolver um trabalho de simulação de cenários para a EC1. Este trabalho envolveu quinze pessoas, entre funcionários $O L 1$ e ECl, com duração de três semanas. Foi um investimento muito alto. Ao final, apresentamos o trabalho para a EC1, destacando redução de custos e alterações em atividades que resultaram em economias de tempo".

No âmbito do controle das operações conjuntas, a OL1, segundo o gerente entrevistado: "tem indicadores chave de performance que são validados pelos clientes $e$ apresentados com freqüência combinada. Com maior experiência no setor, apresentou aqueles que julgava mais adequados e também incorporou sugestões da EC1." O referido entrevistado chama a atenção para o fato de que "na relação OL1/EC1, a confiabilidade do abastecimento é um indicador chave, uma vez que a parada de linha de montagem devido à falta de material é uma falha muito grave".

O gerente entrevistado da EC1 enfatiza os limites e as tolerâncias a falhas, citando o transporte de emergência, que fica à disposição para cobrir deficiências na coleta nos fornecedores: "Podem ocorrer vários problemas $d u$ rante a coleta. Nestes casos, o motorista do transporte avisa a OL1, a qual ativa o plano adequado para aquela contingência. Se é o fornecedor que está atrasado, por exemplo, o transporte segue em frente e a OLl aciona uma terceira transportadora que envia um caminhão para suprir a falha. Posteriormente, OLl e EC1 se reúnem para decidir qual empresa vai arcar com a despesa extra". O entrevistado da EC1 informou que, nos cinco anos de relação com a OL1, nunca ocorreu parada de linha por motivo relacionado ao operador logístico. Atrelado a isto, existem indicadores financeiros que garantem a efetivação da operação ao menor custo possível.

A OL1 tem uma postura pró-ativa, na opinião do seu gerente entrevistado, mas as mudanças sempre estão condicionadas à aprovação da EC1. As alterações de volume de carga, face à variação na produção, são informadas à OL1 com antecedência, gerando decisões de investimento no que se refere a armazéns, veículos e equipamentos. $\mathrm{Na}$ visão do entrevistado: "Se um projeto for desenvolvido em um nível da média gerência, sem autonomia para implantá-lo, é provável que as outras áreas não cooperem. Esse gerente tem que convencer a diretoria primeiro, para, depois, conseguir integrar as várias áreas envolvidas com a logística e implantar os processos necessários." A esse respeito, assinala o fato de que sua empresa mantém funcionários na EC1 para ajudar na organização e gerenciamento da operação, agilizando o planejamento e a execução. Existem funcionários da OL1 trabalhando no interior das plantas da EC1, tanto em Rosário, como em São Caetano do Sul, responsáveis pela atualização da situação das cargas no sistema EC1 e pela emissão de notas fiscais.

Quanto ao sistema de comunicação, o entrevistado da EC1 considera a troca de informações item primordial para que a relação entre as empresas tenha sucesso. Os contatos entre os funcionários dos dois parceiros são efetuados constantemente, tanto pessoalmente, como por telefone ou e-mail. A OL1 possui um gerente responsável para tratar com o cliente, sendo o centro principal de contato para qualquer eventualidade. A idéia é concentrar as atividades em algumas pessoas, para não perder o histórico da relação e manter o atendimento dedicado ao cliente.

A programação de coletas e de entregas do sistema OL1 é informada à EC1, para a reprogramação da sua produção, se necessário. As modificações no sistema EC1 também são passadas automaticamente à OL1.

No que se refere ao compartilhamento de riscos e benefícios, focando a variável disponibilidade para ajudar os ganhos do parceiro, o entrevistado da OL1 assim se expressou: "A ECl desenvolveu embalagens para produtos de um fornecedor de peças de grande volume e baixo peso, de modo a atender alguns requisitos de abastecimento da linha. Quando a OL1 começou a operar com esse fornecedor, percebeu que esta embalagem não es- 
tava dimensionada para um transporte eficiente, porque sua altura não permitia o empilhamento. A OL1 sugeriu, então, que a embalagem tivesse sua altura reduzida em alguns centímetros, cortando os custos de transporte pela metade. A OL1 não ganhou nada com essa iniciativa, ao contrário, perdeu o volume de transporte economizado. Procedeu à mudança visando oferecer melhores práticas logísticas ao cliente".

A confiança é visualizada pelo entrevistado da OL1 a partir de dois aspectos: reputação e construção ao longo do tempo. No que diz respeito à reputação, o entrevistado destacou a tradição e o porte das empresas como elementos geradores. Quanto à construção da confiança ao longo do tempo, ressaltou que "a confiança foi sendo construída entre as pessoas e que, atualmente, é fator consolidado".

Quanto ao estilo do contrato, o entrevistado da EC1 informou que a validade é de três anos. Após este período, a EC1 lança um edital de concorrência no mercado e vence a melhor proposta, sem preferências especiais. $\mathrm{O}$ contrato firmado tem caráter específico, procurando reduzir ao mínimo as interpretações diferentes com relação às atividades, aos processos e às responsabilidades.

No âmbito do componente escopo, a OL1 não disponibilizou valores relativos à porcentagem do faturamento representado pela EC1, afirmando, no entanto, que é um dos seus clientes mais importantes. Ressaltou ainda que o sistema Milk Run implantado pela empresa foi pioneiro na América do Sul, sendo que a OL1 teve participação essencial no processo.

Finalmente, no que diz respeito ao investimento, as empresas se dispõem a compartilhar recursos em infraestrutura, tecnologia e pessoal, investindo continuamente no desenvolvimento de sistemas de informação, treinamento de pessoal e modificação de processos.

\subsection{Relacionamento OL2/EC2}

A OL2 pertence a um grande grupo atacadista, seu maior cliente, cuja experiência data de 1953. Em 1998, a OL2 iniciou suas operações voltadas ao fornecimento de serviços logísticos personalizados, em todo o território nacional, ampliando sua clientela para outros setores de atividade. Com uma frota de 2000 veículos próprios e 52 pontos de transbordo, emprega diretamente 4.500 funcionários.

A EC2 atua no Brasil há 87 anos. Com faturamento anual de duzentos milhões de reais, movimenta 1.600 toneladas de produtos por mês, apenas no que se refere ao mercado de peças de reposição, empregando diretamente 600 funcionários, em 2001. A parceria com operadores logísticos é fato inédito na história da $\mathrm{EC} 2$, conhecida, mundialmente, por sua excelência em logística.

No início de 2002, a EC2 constituiu uma aliança estratégica com a Goodyear, visando o aproveitamento da complementaridade de produtos e de clientela, reduzindo custos logísticos. Na definição da empresa logística que ficaria responsável pelas operações, decidiu-se pela OL2, que já fornecia serviços para a Goodyear. A EC2 operava com um outro operador logístico, desde 1999, passando a trabalhar com a OL2 a partir do primeiro semestre de 2002.

Dentre as dificuldades apresentadas na fase de implementação da parceria, o entrevistado da OL2 comenta: "são três culturas diferentes, a EC2 é sueca, a Goodyear é americana e a OL2 é brasileira. Funcionários das várias áreas das empresas precisam de tempo e treinamento para que possam criar um modo de operação comum."

Considerando a fase em que se encontra a parceria, a atividade de planejamento se realiza a partir de reuniões semanais, envolvendo diretores, gerentes e pessoal operacional. Foram fixadas metas mensais associadas à mudança física do centro de distribuição, passando pela implantação do sistema de informação, chegando à operacionalização das atividades. Foram também especificadas metas a serem atingidas após o período de implantação da parceria. Houve uma reunião entre os três presidentes das empresas envolvidas, para discutir o futuro da parceria. Este tipo de reunião deverá ser repetido com periodicidade ainda não definida.

Com relação ao controle de operações conjuntas, solicitado a se manifestar sobre a avaliação de desempenho e aos medidores de performance utilizados, o entrevistado da OL2 destacou: "Temos indicadores de nível de serviço, de percentual de perda de prazo, de faltas. Com a EC2, temos que entregar, na Grande São Paulo, $90 \%$ dos pedidos em 24 horas e os $20 \%$ restantes em 48 horas. A meta é chegar aos 100\%, em 24 horas. Os medidores foram exaustivamente negociados."

Segundo o entrevistado da EC2, a empresa tem indicadores próprios que foram incorporados pela OL2, após negociação: "Temos indicadores básicos e inquestionáveis do nosso ponto de vista. Temos medição de desempenho diária. Tenho alguns medidores de prazo de entrega. O grupo exige que $98 \%$ das entregas sejam feitas em 24 horas. Eles (a OL2) têm que mostrar a emissão de nota fiscal e o carimbo de recebimento eletrônico, com justificativa de qualquer atraso."

O referido entrevistado ressalta também que, apesar da operação estar a cargo da OL2, é o nome da EC2 que está sendo avaliado pelos clientes.

Ainda, no que se refere ao controle das operações conjuntas, o fornecedor e o cliente destacam que a aproximação entre os funcionários das duas empresas facilita a discussão e a solução de problemas. Assim, a instalação dos departamentos comerciais da EC2 e da Goodyear no interior do Centro de Distribuição da OL2 possibilitou o contato entre os funcionários, eliminando a necessidade de 
reuniões, de modo que sugestões e idéias são discutidas de modo aberto, sem burocracia, gerando decisões rápidas.

As comunicações são facilitadas pela presença física dos funcionários da EC2 no centro de distribuição da OL2. Qualquer informação pode ser tratada pessoalmente e é processada rapidamente. O gerente entrevistado da EC2 ressalta que as reuniões informais são periódicas, havendo reconhecimento do serviço feito e fortalecimento do relacionamento. A diretoria da OL2 entra em contato telefônico com a gerência da EC2 pelo menos duas vezes por dia, fora os contatos pessoais.

As duas empresas têm sistemas próprios de gerenciamento de estoques. Ao iniciar a relação, as empresas criaram uma interface para troca de dados entre seus sistemas de informação. O pessoal da OL2 é encarregado da alteração dos dados no sistema da EC2.

No que se refere ao compartilhamento de riscos e de benefícios, quando ocorrerem mudanças em atividades ou processos que levem à redução de custos, o ganho é repartido entre fornecedor e cliente, incentivando a disponibilidade para ajudar o outro a ganhar. Nesse sentido, o entrevistado da OL2 ressalta que, a partir da implantação de uma melhoria "podemos faturar menos em dada atividade, mas o lucro global será maior."

$\mathrm{Na}$ visão do entrevistado da OL2, a confiança está em construção, já que a relação é recente, ressaltando que a experiência anterior com a Goodyear, considerada de alto nível de confiança, contribuiu de maneira fundamental para alicerçar o relacionamento com a EC2.

O sigilo das informações é item contratual, sendo que os funcionários da OL2 têm acesso ao sistema EC2, envolvendo senhas diferenciadas e informações privilegiadas. Antes da implantação da parceria, os funcionários da OL2 tiveram dois meses de treinamento junto à EC2, nos âmbitos operacional e administrativo.

O contrato tem a duração de cinco anos, com renovação automática por mais cinco, estabelecendo metas para as várias fases da relação, principalmente a inicial, abrangendo os seis primeiros meses de operação. A revisão de preços ocorre anualmente. Conforme informou o entrevistado da OL2, foram necessários seis meses para que as empresas elaborassem o contrato. A formalidade exigida pela OL2 resultou em um contrato bastante específico, composto de duas partes. A primeira define as responsabilidades fiscais, financeiras e de informações. A segunda abrange as operações, rotas de transporte e limite de reajuste dos custos.

O entrevistado da EC2 ressalta que a planilha de custos da OL2 é aberta à EC2, proporcionando flexibilidade à última. Uma vez conhecendo os custos da parceira, pode verificar a adequação ou não de alterar as atividades.

Quanto ao componente escopo, a EC2 tem participação modesta no faturamento da OL2, cerca de $4 \%$ do fa- turamento total. Por sua vez, a OL2 é uma parceira estratégica da EC2, sendo responsável pela movimentação de todo o setor de peças de reposição, em torno de $30 \%$ do volume de vendas desta última. A OL2 executa um amplo conjunto de atividades associado à logística da EC2, envolvendo administração de estoques, transporte, administração do faturamento e, inclusive, o recebimento.

Contratualmente, todo investimento em infra-estrutura é de responsabilidade da EC2. O entrevistado da empresa destaca: "A EC2 decidiu assumir o investimento no centro de distribuição $(C D)$, apostando que o relacionamento com a OL2 será duradouro.” Segundo o entrevistado, "inicialmente, a responsabilidade do investimento seria da OL2, porém, por questão de controle e, considerando a disponibilidade de verbas, decidimos assumir."

O investimento em tecnologia é de responsabilidade da OL2. As empresas trabalham com dois sistemas de informação, trazendo dificuldades tanto para sua instalação quanto para sua alteração. No entanto, esta duplicidade facilita a conferência dos dados, por comparação dos dois sistemas. O entrevistado da EC2 destaca: "Há pessoal da OL2 e da matriz da EC2 trabalhando em conjunto para fazer as adaptações necessárias nos sistemas.. Desenvolvemos uma 'expertise' muito grande no âmbito do desenvolvimento conjunto de sistemas de informação. Sendo assim, nós somos bastante pressionados para que o sistema da OL2 seja, no mínimo, igual ao sistema da EC2."

No que diz respeito aos recursos humanos, o entrevistado da EC2 chama a atenção para a expectativa de que "as fronteiras entre a EC2 e a OL2 sejam invisíveis. Nós devemos ser juntos uma empresa só.”

\subsection{Relacionamento OL3/EC3}

Com sede na Basiléia, Suíça, a OL3 está presente em mais de 140 países, contando com 38.000 colaboradores. Em junho de 1999, adquiriu o controle acionário de uma empresa nacional pioneira na prestação de serviços logísticos e líder no mercado brasileiro. A empresa possui uma carteira formada por grandes empresas de diversos setores, com diversas unidades no território nacional.

A EC3 tem sede nos Estados Unidos e foi fundada em 1904. É um dos maiores fornecedores globais de autopeças para fabricantes de veículos e respectivos mercados de reposição. Opera em cerca de 300 centros industriais, em 34 países, e tem 70.000 funcionários, tendo faturado US\$ 10,3 bilhões, em 2001. Iniciou suas atividades no Brasil ao adquirir uma empresa nacional, em 1945. Atualmente, incorporou várias empresas nacionais, possuindo 19 fábricas, empregando 2.500 funcionários. Fatura US\$ 130 milhões, no Brasil, sendo que 30\% correspondem ao mercado de reposição.

A logística de distribuição de peças para o mercado de reposição está a cargo da OL3, há seis anos. Preocupada com a melhoria dos serviços logísticos prestados, a EC3 
decidiu concentrar seus estoques de peças para reposição em um CD próprio na cidade de Guarulhos-SP.

Antes de iniciar as operações com a OL3, as plantas da EC3 eram responsáveis por sua própria logística, causando uma série de problemas, principalmente associados ao controle de estoques, à quantidade de notas fiscais e de entregas diferentes para o mesmo cliente. Segundo o entrevistado da EC3, ao contratar o operador logístico, a empresa ganhou agilidade e visibilidade no controle de estoques, diminuindo os custos com transporte, por meio da consolidação de cargas.

Há cerca de três anos, parte do staff da EC3 responsável pelo mercado de reposição de peças passou a trabalhar no CD da OL3, agilizando e estreitando a ligação entre as empresas. $\mathrm{O}$ volume de operações passou de 1.500 paletes, em 1999, para 6.500, em 2004. A forma de pagamento dos serviços logísticos também foi alterada, passando de um valor mensal fixo, para o sistema atual, em que a EC3 garante a movimentação mensal de uma quantidade mínima de paletes. Acima dessa quantidade, a remuneração é proporcional, até alcançar um teto.

Com relação às dificuldades enfrentadas na parceria, o entrevistado da OL3 enfatiza o seguinte aspecto: "falta de visualização clara, pelo parceiro, das dificuldades do operador logístico. Às vezes eles querem que seja mantido o nível de serviço atual, reduzindo o custo em $10 \%$. Não dá para fazer mágica. Não quero justificar que a terceirização seja mais cara, mas sim destacar que a terceirização traz vantagens nem sempre mensuráveis. São coisas indiretas. Um cliente trabalhando sozinho pode levar em torno de 72 horas para colocar um pedido. Com o OL3 ele faz isto em 24 horas. Qual o percentual de pedidos não atendido pela empresa-cliente? Muitas vezes, a empresa nem tem este tipo de controle. Com o operador logístico você ganha isto, já que a confiabilidade de estoque é muito maior."

O entrevistado EC3 destaca as dificuldades nas relações pessoais e também a discussão em torno dos custos: "As metas de cada empresa são diferentes. Por mais parceria que exista, cada um tem que cumprir suas metas. Eu luto para ter 60 pessoas do OL3 para atender completamente minhas necessidades. Eles querem colocar menos. No início, o OL3 ganhava uma porcentagem sobre o total de fretes. E eu tenho que abaixar o frete e tinha que forçar para que a OL3 ganhasse menos. Tivemos que mudar o contrato, neste caso. Dependendo também das pessoas, tem aqueles que só trabalham pela cartilha, outros são mais maleáveis e você tem que aprender a tratar com cada um."

As empresas promovem reuniões de planejamento uma vez por mês, se houver necessidade. Segundo o entrevistado da EC3: "O planejamento de algumas atividades rotineiras é efetuado de maneira informal, a partir do contato diário entre o pessoal das duas empresas." Apesar das atividades diárias se constituírem em preocupação importante nas reuniões destinadas ao planejamento, o horizonte envolve períodos maiores, meses e até anos. Os objetivos do planejamento também são amplos, envolvendo desde atividades ou processos, até toda a parceria.

Cabe ressaltar que incorporação de empresas de autopeças pela empresa-cliente impeliu à modificação no esquema geral de trabalho logístico, envolvendo alterações contratuais com o operador logístico. Nestas ocasiões, todo o planejamento existente foi revisto.

Comentando sobre o controle de operações conjuntas, os entrevistados de ambas as empresas informam que estabeleceram, ao longo do tempo, os indicadores de performance mais adequados. Os indicadores, em sua maioria, têm foco no desempenho do operador logístico. Comenta o entrevistado da EC3: "Temos medidores de nível de expedição, quantas linhas de notas fiscais têm que ser feitas por dia. Tudo o que entra no estoque deve estar alocado em 24 horas, desde que não ultrapasse as 50 toneladas /dia previstas em contrato."

$\mathrm{O}$ entrevistado da EC3 informa: "medimos o índice de notas fiscais canceladas. A meta do OL3 é uma nota cancelada a cada 2.000. A acuracidade de inventário também está neste 0,5\%. Se passar disso, a OL3 tem que ressarcir a EC3."

A OL3 disponibiliza vários indicadores de performance a seus clientes. O entrevistado da OL3 comenta: "Estabelecemos metas no que se refere a serviços e à qualidade de operações. O estabelecimento das metas é conjunto. Muitas vezes, nós damos idéias, por conta da experiência. A coisa é bem bilateral neste aspecto."

No que diz respeito à habilidade para executar mudanças, se a alteração atingir apenas uma das empresas, a outra, apesar de ser informada, muitos vezes informalmente, não participa. Se as alterações em processos ou atividades atingirem ambas as empresas, a aprovação conjunta é necessária, procedendo-se à avaliação dos custos envolvidos. O entrevistado da OL3 exemplifica: "Vou implantar um processo de código de barras, então defino o método de trabalho. Neste caso, a forma que vou fazer o trabalho não envolve diretamente a EC3. Por outro lado, se vou usar código de barras para fazer a conferência e emitir uma etiqueta com os dados do cliente, dizendo quais os itens contidos naquela caixa que estou embalando, então envolvemos a EC3, porque a mesma sabe exatamente qual a necessidade do seu cliente."

No que se refere às comunicações, a localização do pessoal da empresa-cliente no interior das instalações do operador logístico garante a troca ágil de informações. Como o entrevistado da OL3 comenta: "Tenho liberdade de ir à sala da EC3 tomar café e contar o que está ha- 
vendo. Trocamos muita informação. Dependemos um do outro. Tentamos manter reuniões sistemáticas, semanais, para verificar a evolução da operação. Quando as reuniões não são tão freqüentes, a operação está normal. Hoje, com a EC3, fazemos reuniões uma vez por mês. É bem dinâmico."

A agilidade logística é assegurada, também, pelos sistemas de informação informatizados. O sistema do OL3 funciona de modo padrão para todos os clientes. Para que as informações possam ser personalizadas e o sistema possa interagir com o sistema do cliente, a OL13 criou sub-rotinas de adaptação.

No âmbito do comprometimento com os ganhos mútuos, o entrevistado da OL3 assim se expressa: "Eu diria que a cooperação é até freqüente. Por exemplo, a EC3 enviava os produtos embalados em caixas com identificação apenas pelo código de barra. Assim, quando o cliente da ECl recebia um pedido grande, ficava difícil para o mesmo encontrar um item específico no interior da embalagem. Pensando nisso, resolvemos desenvolver uma etiqueta para cada caixa, mostrando seu conteúdo. Foi uma mudança que não trouxe benefício para a OL3, porém verificou-se que o cliente ficou mais satisfeito; isto paga tudo. Eu diria que o relacionamento com a EC3 está acima da média, principalmente por estarem junto da gente. Eles sentem as nossas dificuldades e vice-versa. Com outros clientes isto pode não ser tão enraizado. Mas buscamos sempre esta liberdade, esta sinergia. Em alguns momentos, isto não acontece com tanta força."

O entrevistado da EC3 é menos enfático neste assunto: "temos alguma disponibilidade para apoiar, sempre puxando a sardinha para nosso lado."

As empresas consideram o grau de confiança entre elas elevado, ressaltando que as operações normais continuam, mesmo que o contrato possa estar sofrendo modificações. O entrevistado da OL3 comenta: "Quando não existe mudança significativa no processo, não necessariamente ocorre mudança de contrato. Por exemplo, a EC3 tem uma área de assistência técnica aqui dentro, voltada à análise das devoluções de produto por problemas de ordem técnica. Houve um aumento no escopo deste processo, demandando mais espaço e recursos humanos. Tivemos que mexer no lay-out da 'salinha' usada pela EC3."

No que se refere ao estilo do contrato, na visão dos entrevistados, apesar da validade do contrato entre as empresas ser de dois anos, a parceria não tem data para acabar. A cobertura do contrato é ampla, detalhando as atividades mais importantes, como recebimento e conferência, além de definir as especificações de serviço e a acuricidade do estoque.

Analisando a variável participação no faturamento, do componente escopo, verifica-se que a EC3 contribui com $4 \%$ da receita total da OL3. Por sua vez, a OL3 é respon- sável pela logística de aproximadamente $30 \%$ do faturamento da EC3, valor este relativo ao mercado de peças de reposição. O entrevistado da OL1 considera altamente críticas as atividades logísticas desempenhadas: "temos todo o faturamento relativo ao mercado de reposição do cliente em nossas mãos. Se não entregarmos aquilo que ele produziu, seus clientes não vão pagar. Mais crítico que isto, impossível."

Com relação ao componente investimento, as decisões quanto à infra-estrutura são estudadas conjuntamente pelas empresas, definindo a responsabilidade de cada parte. Os investimentos em tecnologia geralmente ficam a cargo da OL3. No que se refere aos recursos humanos, considerando a presença de funcionários da EC3 na planta da OL3, existe o interesse no desenvolvimento de treinamento e aprendizagem conjunta.

\section{Análise dos resultados}

Com base na descrição dos resultados das entrevistas, foram construídas as Tabelas 1 e 2, apresentando uma síntese dos mecanismos de gestão utilizados nos três casos analisados - OL1/EC1; OL2/EC2 e OL3/EC3 - a partir da qual são identificados aspectos centrais associados ao grau de integração entre os operadores logísticos e suas respectivas empresas clientes.

Assim, o componente planejamento das operações conjuntas demonstrou ser objeto de grande atenção por parte das agentes das parcerias analisadas, evoluindo para mecanismos complexos e desenvolvidos, o que evidencia a disposição das empresas em investir tempo e recursos para integrar atividades e processos.

O foco da avaliação das atividades recai sobre os operadores logísticos, sendo que os índices de desempenho, embora propostos por uma das partes, foram amplamente discutidos. As alterações nos processos são bem-vindas, necessitando de aprovação de ambas as partes. As empresas foram unânimes em afirmar que o parceiro necessita ser informado, até mesmo para que possa tomar as providências necessárias para a implantação do novo processo ou atividade.

A cooperação e o compartilhamento de benefícios obtidos a partir do desenvolvimento conjunto de processos não se revelaram um aspecto consensual. Destaca-se a parceria OL3/EC3, marcada, de um lado, pela existência de conflitos em torno do custo e do preço dos serviços e, de outro, por percepções diferentes sobre o compartilhamento de riscos e de benefícios. Enquanto a OL3 demonstra empenho, a EC3 indica apenas disponibilidade para ajudar, desde que obtenha algum benefício.

A proximidade física, no local de trabalho, das equipes operacionais das diferentes empresas parceiras parece fortalecer a parceria, no que diz respeito à confiança e ao compartilhamento de riscos e de benefícios. Ao agi- 
Tabela 1. Formas de Coordenação das Atividades.

Planejamento das Atividades Conjuntas Controle das Operações Conjuntas Sistema de Comunicações

-índices de desempenho estabelecidos de - compartilhamento de infor-

-elevada freqüência de reuniões, envolvendo vá- comum acordo;

rios níveis hierárquicos.

- mecanismos para cobrir contingências. ção do cliente;

- contatos freqüentes entre os funcionários das duas empresas.

OL2/EC2 -centrado na operação e na definição de metas; -indicadores de desempenho definidos - integração das equipes opera-exige a participação dos níveis hierárquicos su- pela empresa cliente; periores.

-demora em se chegar a um acordo; $\quad$-cada empresa mantém um sis-avaliação do desempenho concentrada tema de informação. no prazo de entrega e no estoque.

OL3/EC3 -planejamento operacional não é formalizado; - conflitos em torno do custo das opera- - integração das equipes opera-planejamento estratégico envolve processos e a ções e do preço do serviço; cionais; configuração da parceria.

-foco no desempenho do operador logís- - integração dos sistemas de intico;

-estabelecimento de metas conjuntas;

Tabela 2. Processo de Construção e de Sustentação da Parceria.

\begin{tabular}{|c|c|c|c|}
\hline & OL1/EC1 & OL2/EC2 & OL3/EC3 \\
\hline $\begin{array}{l}\text { Compartilhamento de riscos e } \\
\text { benefícios }\end{array}$ & $\begin{array}{l}\text {-desenvolvimento conjunto de } \\
\text { processos e de embalagens. }\end{array}$ & $\begin{array}{l}\text { - repartição de benefícios a partir } \\
\text { de mudanças em processos. }\end{array}$ & $\begin{array}{l}\text { - visões diferentes sobre a exis- } \\
\text { tência de cooperação. }\end{array}$ \\
\hline Confiança & $\begin{array}{l}\text {-associada à tradição e ao tempo } \\
\text { de relacionamento. }\end{array}$ & $\begin{array}{l}\text { - em construção (relacionamento } \\
\text { recente). }\end{array}$ & $\begin{array}{l}\text { - elevada confiança e alta flexibi- } \\
\text { lidade nas relações. }\end{array}$ \\
\hline Estilo do contrato & $\begin{array}{l}\text {-detalhado e com definições pre- } \\
\text { cisas de atividades, processos e } \\
\text { responsabilidades. }\end{array}$ & $\begin{array}{l}\text { - específico, com definição pre- } \\
\text { cisa de responsabilidades. }\end{array}$ & $\begin{array}{l}\text { - a parceria não tem prazo para } \\
\text { terminar; } \\
\text { - cobertura ampla. }\end{array}$ \\
\hline Investimentos conjuntos & $\begin{array}{l}\text {-infra-estrutura, pessoal e tecno- } \\
\text { logia. }\end{array}$ & $\begin{array}{l}\text { - a EC2 se encarrega da infra-es- } \\
\text { trutura e a OL2 da tecnologia. }\end{array}$ & $\begin{array}{l}\text { - no âmbito do desenvolvimento } \\
\text { de recursos humanos. }\end{array}$ \\
\hline
\end{tabular}

lizar a troca de informações entre as partes, a proximidade aumenta a integração no âmbito operacional e, por conseqüência, facilita a tomada de decisões. Qualquer informação pode ser tratada pessoalmente e é processada rapidamente. As reuniões informais são periódicas, havendo reconhecimento do serviço feito e fortalecimento do relacionamento.

O componente estilo do contrato envolve a parte mais formal do relacionamento associada à edificação de um contexto geral das relações, enfocando situações de resolução de dúvidas e de conflitos entre as partes. A cobertura dos contratos - especificação formal das atividades a serem desenvolvidas - varia bastante em função da cultura das empresas envolvidas. Destaca-se, no entanto, a preocupação com o detalhamento do contrato.

Embora os contratos sejam estabelecidos em bases estreitas e num contexto formal, a relação se mantém e se desenvolve a partir de laços de confiança, que se consolidam com base no relacionamento intenso entre os funcionários - de diversos departamentos e níveis hierárquicos - de ambas as empresas e na efetivação de investimentos conjuntos.

$\mathrm{O}$ investimento conjunto é um aspecto amplamente discutido entre prestadores de serviço e empresa-cliente.
As empresas tendem a especificar a divisão de responsabilidades, cabendo, de modo geral, ao operador logístico o investimento em tecnologia e em sistemas de informação e à empresa cliente o investimento em infra-estrutura.

Embora não se tenha procedido, conforme sugerido por Lambert et al., a uma quantificação de cada uma das variáveis consideradas, a pesquisa evidenciou um elevado grau de integração entre as empresas clientes pertencentes à cadeia automotiva e os operadores logísticos. Os três casos analisados - OL1/EC1, OL2/EC2 e OL3/EC3 - podem ser enquadrados como tipo III - parceria altamente integrada, em que cada parte enxerga a outra como extensão da sua própria organização, não existindo uma data para o término da parceria.

Em primeiro lugar, além da estreita integração no âmbito do planejamento e do controle das operações conjuntas, as relações encontradas são personalizadas e francas, baseadas em confiança mútua, com graus variáveis de compartilhamento de riscos e benefícios. Ademais, a intensa troca de informações ocorre em um contexto de interfaces comuns, configurando um fluxo de comunicação de via dupla.

A OL1 efetivou um conjunto de investimentos específicos obtendo, em contrapartida, a exclusividade por 
parte da empresa cliente e o interesse estratégico no aprofundamento do relacionamento. Em outras palavras, cada parte trouxe ou um grande percentual de seu negócio ou um conjunto significativo de atividades para a parceria. No caso OL2/EC2, a empresa cliente decidiu transformar o operador logístico em um parceiro estratégico, arcando com o investimento em um centro de distribuição e incentivando a quebra das fronteiras entre as duas organizações. O operador logístico, por sua vez, respondeu envolvendo-se com os projetos de sistemas de informação e de treinamento de pessoal, oferecidos pela empresa cliente, e aprofundando o leque de atividades oferecidas. No caso OL3/EC3, existe uma elevada dependência da empresa cliente, vis-à-vis, o operador logístico, sem, no entanto, provocar sérios conflitos, destacando-se os imanentes ao preço dos serviços. Os parceiros buscam o compartilhamento de investimentos em infra-estrutura e no âmbito dos recursos humanos.

Em segundo lugar, o elevado grau de integração das parcerias está fortemente associado à atuação dos operadores logísticos em atividades essenciais ao processo produtivo das empresas clientes. As atividades envolvem não só armazenagem e transporte dos produtos, mas o controle de aspectos burocráticos e financeiros, bem como a própria "saúde" da marca em questão. Destacase, na parceria OL1/EC1, a influência direta do operador logístico nas operações da empresa cliente, em particular na coordenação dos fornecedores e no planejamento do sistema de embalagens. Esta é uma função especializada que implica em custos e investimentos especiais, envolvendo conscientização e treinamento dos fornecedores para que possam se integrar ao sistema de trabalho denominado Milk Run.

\section{Conclusão}

Considerando o objetivo do trabalho - identificar os mecanismos efetivos para a organização, a operação e o controle da parceria logística, na cadeia automotiva -, o modelo proposto por Lambert et al. revelou-se um poderoso instrumento de diagnóstico e análise. $\mathrm{O}$ arcabouço abre a oportunidade não somente de análise da viabilidade de constituição de uma parceria, mas considera o grau apropriado de integração.

A pesquisa empreendida deixou patente não só o caráter estratégico dos operadores logísticos associado à importância da obtenção da sincronização dos fluxos de materiais e de informações, mas, principalmente, a relevância das formas de integração entre os agentes. Na cadeia automotiva, mais que fornecedores de serviços terceirizados, os operadores logísticos trabalham em estreito contato com as empresas clientes, tornando-se parceiros de negócios.

Nesse sentido, partindo do pressuposto de que o sucesso das parcerias com agentes especializados nas ativi- dades logísticas depende do tipo e da natureza do arranjo subjacente à relação fornecedor-cliente, o trabalho aponta para alguns pontos essenciais.

Em primeiro lugar, com exceção da variável escopo, o conjunto de variáveis estudadas - planejamento e controle das atividades conjuntas, sistema de comunicações, compartilhamento de riscos e benefícios, estilo do contrato, confiança e investimentos em conjunto - possibilitou uma análise precisa do processo de gestão da parceria e da identificação do grau de integração entre as partes.

Ressalta-se a importância das relações humanas aprofundadas no decorrer do tempo. O elevado grau de integração entre as partes está fortemente atrelado à existência de funcionários do cliente trabalhando nas instalações do prestador de serviços e, mais do que a simples presença física, as relações pessoais são incentivadas nos vários níveis hierárquicos. As dificuldades apresentadas são inerentes à coordenação das atividades entre as empresas, sendo que o fato de serem expostas abertamente reforça o interesse no alcance do bom relacionamento. Destaca-se que o início das operações conjuntas pode ser marcado pela presença de disfunções associadas às dificuldades de planejamento, evoluindo, no entanto, para um maior comprometimento entre as partes, a partir da maior interação/comunicação entre as empresas.

Em segundo lugar, o planejamento, o controle e o sistema de comunicações apresentaram-se como variáveis interdependentes. Quanto melhor o sistema de comunicações entre os parceiros, mais fácil é o planejamento e o desenvolvimento das atividades.

Em terceiro lugar, para que a relação entre as empresas possa evoluir para uma parceria do tipo III, a pesquisa demonstrou a importância da construção da confiança entre as partes. Partindo da premissa básica de que as empresas têm um nome a zelar e, portanto, são idôneas, a construção da parceria envolve atitudes coerentes, éticas e independentes de contrato. Confiança e comprometimento com o sucesso mútuo fortalecem a relação, permitindo graus cada vez maiores de integração de atividades e processos. Por meio do comprometimento, os parceiros podem avançar na direção dos investimentos conjuntos.

Em quarto lugar, no que se refere à variável estilo do contrato, ao contrário da visão de Lambert et al. para o caso de parcerias do tipo III - altamente integradas -, a pesquisa constatou a preocupação dos agentes com o detalhamento e a clara definição de responsabilidades e prazos.

Finalmente, a situação identificada em uma das parcerias analisadas, na qual o operador logístico atuou na gestão de fornecedores da empresa cliente, levanta a possibilidade do primeiro atuar como um agente integrador da cadeia de suprimentos.

Abrem-se novas oportunidades de pesquisa, associadas à investigação da inter-relação entre os mecanismos 
de coordenação da atividade e os mecanismos de construção e de sustentação da relação, como, por exemplo, a intensidade da troca de informações e o aumento da confiança. Da mesma forma, devem ser levados a efeito estudos longitudinais focados no processo de evolução dos mecanismos de gestão do relacionamento, propiciando a visualização dos ajustes efetuados. Não menos importante é o estudo dos contratos nas parcerias logísticas, procurando identificar a sua relação com a criação e a consolidação da confiança entre as partes.
BABA, M. L. Two Sides to Every Story: An Ethnohistorical Approach to Organizational Partnerships. City and Society, Berkeley (Los Angeles), v. 2, n. 2, p. 70-87, December. 1988.

BAGCHI, P. K. e VIRUM, H. European Logistcs Alliances: A Management Model. The International Journal of Logistics Management, Cambridge (MA), v. 7, n.1, p. 93-108, April. 1996.

BOLUMOLE, Y. Evaluating the Supply Chain Role of Logistics Service Providers. The International Journal of Logistics Management, Cambridge (MA), v. 14, n. 2, p. 93-107, November. 2003.

BOYSON, S., et al. Managing Effective Third Party Logistics Relationships. What Take? Journal of Business Logistics, Oak Brook (Illinois), v. 20, n. 1, p. 73-99, April. 1999.

BOWERSOX, D. J. et al. Leading Edge Logistics: Competitive Positioning for the 1990`s Oak Brook (Illinois): Council of Logistics Management, 1989. 115 p.

CHRISTOPHER, M. Logística e gerenciamento da cadeia de suprimentos: estratégias para a redução de custos e melhoria dos serviços. Tradução de Francisco Roque Monteiro Leite. 2a reimpr. da 1 ed. São Paulo: Pioneira, 2001. 240 p.

DWYER, R.; SCHURR, P. e OH, S. Developing BuyerSeller Relationships. Journal of Marketing, Chicago (Illinois), v. 51, n. 2, p. 11-27, April. 1987.

ELLRAM, L. M. Partnering Pitfalls and Success Factors. International Journal of Purchasing and Materials Management, Tempe (Arizona), v. 31, n. 3, p. 36-44, August. 1995.

FLEURY, P. F.; WANKE, P. e FIGUEIREDO, K. F. (org.). Logística empresarial: a perspectiva brasileira. São Paulo: Atlas, 2000. 372 p.

GARDNER, J. T.; COOPER, M. C. e NOORDEWIER, T. Understanting Shipper-Carrier and Shipper-Warehouser Relationships: Partnerships Revisited. Journal of Business Logistics, Oak Brook (Illinois), v. 15, n. 2, p. 121-143, November. 1994.
GUILHON, B. Technologie, Organisation et Performances: Les Cas de la Firme-Reseau. Revue d'Economie Politique, Paris, v. 102, n. 4, p. 563-592, Jul-Ago. 1992.

HALLDORSSON, A e SKJOTT-LARSEN, T. Developing logistics competencies through third-party logistics relationships. International Journal of Operations \& Production Management, Cambridge (MA), v. 24, n. 2, p. 192-206, February. 2004.

KNEMEYER, M. e MURPHY, P. R. Is the glass half full or half empty? An examination of user and provider perspectives towards third-party logistics relationships. International Journal of Physical Distribution \& Logistics Management, Cambridge (MA), v. 35, n. 10, p. 708-727, October. 2005.

LA LONDE, B. J. e COOPER, M. C. Partnerships in Providing Customer Service: A Third-party Perspective. Oak Brook (Illinois): Council of Logistics Management, $1989.96 \mathrm{p}$.

LAMBERT, D.; EMMELHAINZ, M. A. e GARDNER, J. T. Developing and Implementing Supply Chain Partnerships. The International Journal of Logistics Management, Cambridge (MA), v. 7, n. 2, p. 1-17, november. 1996.

Building Successful Logistics Partnerships. Journal of Business Logistes, Oak Brook (Illinois), v. 20, n. 1, p. 165-182, april. 1999.

LAMMING, R. Beyond Partnership: strategies for innovation and lean supply. New York: Prentice-Hall, 1993. 299 p.

LIEB, R. C. e RANDALL, H. L. A Comparison of the Use of Third-Party Logistics Services by Large American Manufacturers, 1991,1994, and 1995. Journal of Business Logistics, Oak Brook (Illinois), v. 17, n. 1, p. 305-320, april. 1996.

MILES, R. e SNOW, C., Network organizations: new concepts for new forms. California Management Review, Berkeley, v. 28, n. 3, p. 62-73, spring. 1987.

MOORE, K. R. Trust and relationship commitment in logistics alliances: a buyer perspective. International 
Journal of Purchasing and Materials Management, Tempe (Arizona), v. 34, n. 4, p. 24-37, November. 1998.

NOVAES, A. G. Logistica e gerenciamento da cadeia de

Distribuição: estratégia, operação e avaliação. Rio de Janeiro: Campus, 2001. 409 p.

SELLTIZ, C., et al. Métodos de Pesquisa nas Relações Sociais. Tradução de Dante Moreira Leite. 3 ed. São Paulo: Ed. da Universidade de São Paulo, 1974. 674 p.

SINKOVICS, R. R. e ROATH, R. Strategic orientation, capabilities, and performance in a manufacturer-3PL relationship. Journal of Business Logistics, Oak Brook (Illinois), v. 18, n. 2, p. 163-189, November. 2004.

STUART, I. Supplier Partnerships: Influencing Factors and Strategic Benefits. International Journal of Purchasing and Materials Management, Tempe (Arizona), v. 29, n. 4, p. 22-28, November. 1993.
STUART, I. e McCUTCHEON, D. Problem Sources in Establishing Strategic Supplier Alliances. International Journal of Purchasing and Materials Management, Tempe (Arizona), v. 31, n. 1, p. 2-9, February. 1995.

WEBER, M. Economia y Sociedad: esbozo de sociologia comprensiva. Tradução de Jose Medina Echevarria. 1 ${ }^{\mathrm{a}}$ ed. em espanhol. México: Fundo de Cultura Economica, 1944. $1273 \mathrm{p}$.

WILLIAMSON, O. E. The Economic Institutions of Capitalism: firms, markets, relational contracting. New York: The Free Press, 1985. 450 p.

YIN, R. K. Estudo de Caso: planejamento e métodos. Tradução de Daniel Grassi. 2a ed. Porto Alegre: Bookman, 2001. $205 \mathrm{p}$.

\section{INTEGRATION OF CLIENT COMPANY AND LOGISTICS OPERATOR: AN ANALYSIS OF THE AUTOMOTIVE CHAIN}

Abstract

This paper identifies and analyzes the mechanisms of coordination between logistics operators and client companies in the automotive sector, covering the main approaches in logistic partnerships. Special emphasis is given to the model proposed by Lambert et al. (1996). The methodology is based on the description and analysis of three case studies. This study revealed the existence of a high degree of integration between the client companies and their logistics operators. The three cases analyzed here were identified as type III - highly integrated partnerships, albeit presenting differences among the coordination mechanisms employed, according to the type and nature of the partnership.

Keywords: logistics operator, partnerships, coordination mechanisms, degree of integration. 